\title{
Epitope characterization of the protective monoclonal antibody VN04-2 shows broadly neutralizing activity against highly pathogenic H5N I
}

\author{
Angeline PC Lim, Steven KK Wong, Annie HY Chan, Conrad EZ Chan, \\ Eng Eong Ooi and Brendon J Hanson*
}

Address: Defence Medical and Environmental Research Institute, DSO National Laboratories, 27 Medical Dr., 117510, Singapore

Email: Angeline PC Lim - lpeichie@dso.org.sg; Steven KK Wong - wkakhuen@dso.org.sg; Annie HY Chan - choiyi@dso.org.sg; Conrad EZ Chan - cenzuo@dso.org.sg; Eng Eong Ooi - oengeong@dso.org.sg; Brendon J Hanson* - hbrendon@dso.org.sg

* Corresponding author

Published: II July 2008

Virology Journal 2008, 5:80 doi:10.1 I86/1743-422X-5-80

This article is available from: http://www.virologyj.com/content/5///80

(C) 2008 Lim et al; licensee BioMed Central Ltd.

This is an Open Access article distributed under the terms of the Creative Commons Attribution License (http://creativecommons.org/licenses/by/2.0), which permits unrestricted use, distribution, and reproduction in any medium, provided the original work is properly cited.
Received: 17 April 2008

Accepted: II July 2008

\begin{abstract}
The monoclonal antibody VN04-2 was previously shown to protect mice against lethal A/Vietnam/ I203/04 H5NI virus challenge when administered pre- and post-infection. In this study, we characterized the binding requirements of this antibody using direct binding to hemagglutinin and neutralization assays with $\mathrm{H} 5 \mathrm{NI}$ virus-like particles (H5NI-VLP) of eight recent $\mathrm{H} 5 \mathrm{NI}$ strains representing the major mutations within the 140s antigenic loop. Binding was clade independent and 3 mutations within this antigenic region are required before escape is possible, suggesting that apart from the $\mathrm{H} 5 \mathrm{NI}$ viruses circulating in Indonesia, VN04-2 may provide protection against $\mathrm{H} 5 \mathrm{NI}$ viruses from all other regions.
\end{abstract}

\section{Findings}

In 1997, human disease was first reported due to direct transmission from poultry of highly pathogenic avian influenza A virus (HPAI) of the subtype $\mathrm{H} 5 \mathrm{~N} 1$, resulting in the death of 6 of the 18 infected individuals [1-3]. Increased geographical distribution (H5N1 has been reported in a variety of birds from over 50 countries) coupled with continued evolution of H5N1 viruses and an immunologically naïve human population highlight the pandemic potential of these viruses [4,5]. Virus spread among the human population has been limited and largely remains the result of direct bird-to-human transmission. As of mid-January 2008, there have been 349 reported cases of human $\mathrm{H} 5 \mathrm{~N} 1$ infection with a high mortality rate resulting in the death of 216 individuals [6]. Recently, we and others have reported therapeutic efficacy of passive immunization in a HPAI H5N1 mouse model with either humanized mouse $\mathrm{mAb}$, equine $\mathrm{F}\left(\mathrm{ab}^{\prime}\right)_{2}$, or human $\mathrm{mAb}$, highlighting its potential as a viable treatment option in human cases of H5N1 [7-9]. Indeed, survival of a person infected with HPAI H5N1 has been reported after treatment with convalescent plasma [10]. A potential drawback to the use of specific mAb is that the high mutation rate of influenza viruses particularly in the antigenic regions means that escape from the protective effect of these antibodies may be rapid. In the case of our humanized mAb VN04-2 (also termed 15A3) specific for the 140s antigenic loop, hemagglutination inhibition (HI) assay data suggested an absolute requirement for lysine at position $140[8,11]$. However, mutation of H5N1 viruses outside of antibody binding sites have been shown to negatively affect the performance of the viruses in $\mathrm{HI}$ assays, suggesting that in some cases a negative $\mathrm{HI}$ assay result may be more a limitation of the assay rather 
than lack of antibody binding [12]. Here we evaluated binding of VN04-2 to a variety of H5 hemagglutinins (HA) independent of the HI assay, to determine the actual effects mutations in this region of the HA gene has on antibody binding and the utility of the antibody for protection against recently circulating $\mathrm{H} 5 \mathrm{~N} 1$ viruses.

The mAb VN04-2 was raised against the HA of A/Vietnam/ $1203 / 04$, therefore to select the HAs to be used in this study, we aligned all the HA sequences from H5N1 viruses isolated throughout 2005 and 2006, that were deposited into the Influenza Virus Resource and was maintained by NCBI, against this HA [13]. Focusing on mutation within the 140s loop antigenic region, the HA sequences could be divided into eight groups, and a representative of each of these was selected to be used in the antibody binding analysis (Table 1). The cDNAs encoding the HA1 subunits of the selected HAs were produced by a combination of PCR based methods and the fidelity of each clone was confirmed by sequencing. In order to produce the HA proteins, we used the recombinant baculovirus expression method described for determination of the H5 HA structure, where the transmembrane domain had been replaced by the 'foldon' trimerization sequence, allowing for expression of soluble HA trimers which could be purified by virtue of the carboxyl terminal hexa-histidine tag [14]. Following introduction of the foldon sequence into the HA2 of A/Vietnam/1203/04 and insertion into plasmids containing each of the HA1s listed in table 1, recombinant baculoviruses were produced and used to infect Sf9 insect cells. All nine of the HA-foldons could be purified from culture medium using talon affinity resin and cleavage into HA1 and HA2 subunits with trypsin indicated that the proteins were correctly folded (data not shown).
To examine the ability of the humanized antibody VN042 to bind to the selected HAs, ELISA was performed. Figure 1 shows the level of binding detected with $1 \mathrm{ug} / \mathrm{mL}$ VN04-2 antibody and several serial dilutions, after the various HA-foldons were coated onto ELISA plates at 500 ng/well. Highest signal was observed with the immunogen HA from A/Vietnam/1203/04, while the HAs from A/ Indonesia/5/05 and A/Ck/Indonesia/R60/05 were unable to bind VN04-2 at all, suggesting that 3 mutations within the 140s loop antigenic site are required to escape antibody binding, a conclusion supported as the remaining HAs showed binding of VN04-2 albeit at varying degrees. Interestingly, the HA from A/Dk/Vietnam/376/05 which only contains mutations within the 140s loop showed similar binding characteristics to that of A/Vietnam/1203/ 04. Therefore, the amino acids within the 140s loop may be the main determinants of antibody binding for VN042 , but residues outside of this region may also contribute to the overall antibody binding affinity. Previous studies with H3N2 influenza A virus have indicated that antibodies against the 140s loop antigenic site with association constants $\left(\mathrm{K}_{A}\right)$ in the $10^{6} \mathrm{M}^{-1}$ range can bind HA by ELISA and exhibit neutralizing efficacy [15]. Therefore to definitively measure the actual binding kinetics of VN04-2 to the various HAs that showed binding in the ELISA assay, we also measured the affinity of VN04-2 for the various HA-foldons using Biacore SPR analysis. The antibody showed a range of association constants for the HAs with the highest calculated against A/Vietnam/1203/04 (2.63 $\times$ $10^{8} \mathrm{M}^{-1}$ ) and the lowest calculated against the lowest ELISA binding A/CK/Ivory Coast/1787/06 (1.93 × 107 $\mathrm{M}^{-}$ $\left.{ }^{1}\right)$, indicating good agreement between the ELISA data and the actual antibody/HA $\mathrm{K}_{\mathrm{A}}$ (Table 2) Together, these results deduce that the absolute requirement for lysine at

Table I: Position of mutation in the selected HAIs compared to A/Vietnam/ / 203/04a

\begin{tabular}{|c|c|c|c|c|c|c|c|c|c|c|c|c|c|}
\hline \multirow{3}{*}{ Virus } & \multirow{3}{*}{ Clade $^{b}$} & \multicolumn{12}{|c|}{ Amino acid position } \\
\hline & & \multirow[b]{2}{*}{94} & \multirow[b]{2}{*}{124} & \multirow[b]{2}{*}{129} & \multicolumn{5}{|c|}{ I40s Loop } & \multicolumn{3}{|c|}{ I50s Loop } & \multirow[b]{2}{*}{189} \\
\hline & & & & & 136 & 137 & 138 & 140 & $|4|$ & 154 & 155 & 156 & \\
\hline A/Vietnam/I203/04 & 1 & $\mathrm{D}$ & S & $\mathrm{L}$ & $P$ & $Y$ & $\mathrm{Q}$ & $\mathrm{K}$ & $S$ & $\mathrm{~N}$ & S & $\mathrm{T}$ & K \\
\hline A/DK/Vietnam/376/05 & I & . & . & . & . & . & . & $\mathrm{N}$ & $P$ & . & . & . & . \\
\hline A/BhGs/Qing Hai/65/05 & 2.2 & $\mathrm{~N}$ & $\mathrm{D}$ & S & . & . & . & $\mathrm{R}$ & . & . & $\mathrm{N}$ & $A$ & $\mathrm{R}$ \\
\hline $\mathrm{A} / \mathrm{CK} /$ Ivory Coast/I787/06 & 2.2 & $\mathrm{~N}$ & $\mathrm{D}$ & S & . & $\mathrm{H}$ & . & $\mathrm{R}$ & . & $\mathrm{D}$ & $\mathrm{N}$ & $A$ & $\mathrm{R}$ \\
\hline A/Zhe Jiang/I6/06 & 2.3 .4 & $\mathrm{~N}$ & $\mathrm{D}$ & $S$ & . & . & . & $\mathrm{T}$ & $P$ & . & $N$ & . & . \\
\hline A/DK/Guangzhou/20/05 & 9 & . & $\mathrm{N}$ & $S$ & . & . & $\mathrm{L}$ & . & $P$ & . & $\mathrm{N}$ & $A$ & . \\
\hline A/Indonesia/CDC597/06 & 2.1 .2 & $\mathrm{~N}$ & $\mathrm{D}$ & . & . & . & L & $\dot{R}$ & . & . & $\mathrm{N}$ & . & $\mathrm{R}$ \\
\hline $\mathrm{A} /$ Indonesia/5/05 & 2.1 .3 & $S$ & $\mathrm{D}$ & S & . & . & L & S & $P$ & . & . & . & $\mathrm{R}$ \\
\hline $\mathrm{A} / \mathrm{CK} /$ Indonesia/R60/05 & 2.1 .1 & $\mathrm{~N}$ & $\mathrm{D}$ & S & S & . & L & $\mathrm{D}$ & $P$ & . & . & A & $\mathrm{R}$ \\
\hline
\end{tabular}

${ }^{a}$ residues similar to $\mathrm{A} / \mathrm{Vietnam} / \mathrm{I} 203 / 04$ are marked by a period

${ }^{b}$ Clade nomenclature as suggested by WHO [19] 
Table 2: Equilibrium association $\left(K_{A}\right)$ and dissociation $\left(K_{D}\right)$ constants of VN04-2 with HA

\begin{tabular}{llc}
\hline Virus of HA-Foldon & $K_{A}\left(\mathrm{M}^{-1}\right)$ & $K_{D}(\mathrm{M})$ \\
\hline A/Vietnam/I203/04 & $2.63 \times 10^{8}$ & $3.8 \times 10^{-9}$ \\
A/DK/Vietnam/376/05 & $9.72 \times 10^{7}$ & $1.03 \times 10^{-8}$ \\
A/BhGs/Qing Hai/65/05 & $3.08 \times 10^{7}$ & $3.25 \times 10^{-8}$ \\
A/CK/lvory Coast/1787/06 & $1.93 \times 10^{7}$ & $5.17 \times 10^{-8}$ \\
A/Zhe Jiang//6/06 & $2.36 \times 10^{7}$ & $4.24 \times 10^{-8}$ \\
A/DK/Guangzhou/20/05 & $5.46 \times 10^{7}$ & $1.83 \times 10^{-8}$ \\
A/Indonesia/CDC597/06 & $3.38 \times 10^{7}$ & $2.96 \times 10^{-8}$ \\
\hline
\end{tabular}

residue 140 , as indicated previously by the $\mathrm{HI}$ assay, was most likely due to assay limitations rather than the actual binding properties of the antibody. However, as limited mutation in the 140s antigenic loop and elsewhere lowers the affinity of VN04-2 interaction with HA, we wanted to determine if the lower affinity correlated to a loss of neutralization.

Recently, virus-like particles (VLP) built on a retroviral core particle, harboring the surface proteins of Venezuelan equine encephalitis virus and $\mathrm{H} 5 \mathrm{~N} 1$ have shown their potential as vaccine candidates and also through inclusion of either luciferase or GFP reporter genes, utility as a substitute for live virus in cell based neutralization assays [16-18]. The VLP utilizes the core particle of the moloney murine leukemia virus and as it is non-replicative, is ideally suited for pseudotyping of high containment viruses such as H5N1. To enable expression of H5N1-VLPs, we cloned the HA1 cDNAs described in table 1 together with HA2 of A/Vietnam/1203/04 into the CMV promoter driven expression vector, $\mathrm{pXJ}$ and the $\mathrm{N} 1$ neuraminidase

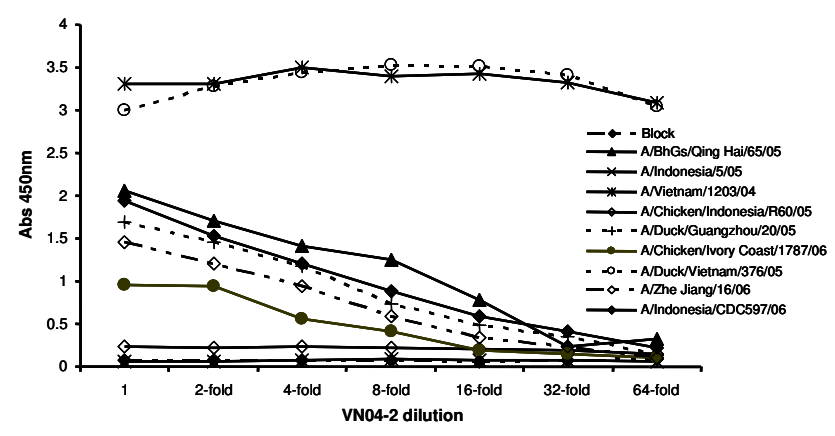

Figure I

Affinity of VN04-2 against various HA-foldons determined by ELISA. Purified HA-foldons from the indicated $\mathrm{H} 5 \mathrm{NI}$ viruses (outlined in table I) were used to coat ELISA plates and incubated with VN04-2 (I ug/mL) or its 2 fold serial dilutions, bound antibody was detected with antihuman IgG conjugated to HRP and visualized using TMB. Data shown are the averages from two independent experiments.
(NA) of A/Vietnam/1203/04 into pCI (Promega). The plasmids encoding the core particle and GFP reporter gene, pVPack-GP and pFB-hrGFP respectively were purchased from Stratagene. Following introduction of the plasmids into HEK293, the production of H5N1-VLPs was confirmed by immunoblots and observation of GFP in MDCK cells after incubation with the HEK293 culture medium (data not shown).

To determine the ability of VN04-2 to neutralize transduction of the various H5N1-VLPs, HEK293 culture supernatants were incubated with $2 \mathrm{ug} / \mathrm{mL}$ VN04-2 for $60 \mathrm{~min}$ prior to the addition to MDCK, and 3 days later the number of cells expressing GFP was determined by flow cytometry. As highlighted in table 3, except for the H5N1VLPs produced using the HAs from A/Indonesia/5/05 and A/Ck/Indonesia/R60/05, VN04-2 was able to neutralize the transduction of all the H5N1-VLPs tested. It is worth noting that HAs which exhibited the lowest affinity for VN04-2 also exhibited less neutralization, indicating a correlation between direct binding affinity and effectiveness of viral neutralization for a known neutralizing antibody. In addition, when we used the culture supernatants incubated with VN04-2 in a HI assay, inhibition was only observed when the H5N1-VLPs HA had aspartic acid residue 94 (Table 3), which is in agreement with the HI data reported by Chen et al, presented in table 1[11]. Taken together the results support the hypothesis that the absolute requirement of lysine at residue 140 was due to a limitation of the assay and not the antibody. While in vitro data does not always reliably predict in vivo efficacy [7]. The demonstrated in vivo efficacy of VN04-2, coupled with the relative insensitivity of this antigenic region to the low $\mathrm{pH}$ induced conformational changes of HA, prior to fusion as seen in H3N2 [15]: we believe that in this case, in vitro binding data could be indicative of in vivo efficacy. However, this can only be confirmed with empirical data.

In conclusion, our results show that the protective humanized antibody VN04-2 we have previously described is capable of tolerating 3 mutations within its epitope, the 140s loop and that residues outside of this loop while not being major determinants of antibody binding do affect the affinity of the antibody binding to HA. In addition, our results indicate that the previous requirements for VN04-2 binding derived from HI assay data may have been due to assay limitations rather than the actual antibody binding and adds to an increasing amount of evidence questioning the usefulness of $\mathrm{HI}$ assays as a measure of neutralization, or for epitope mapping. The HA clones described here were representative of the antigenic drift observed during 2005 and 2006 within this antigenic region, and is still the case for $\mathrm{H} 5 \mathrm{~N} 1$ strains isolated throughout 2007, suggesting that apart from the 
Table 3: Determination of VN04-2 neutralization of H5NI-VLPs

\begin{tabular}{|c|c|c|c|}
\hline \multirow[b]{2}{*}{ Virus } & \multicolumn{2}{|c|}{ H5NI-VLPa } & \multirow{2}{*}{$\begin{array}{l}\text { Virus }^{b} \\
\text { HI titer }\end{array}$} \\
\hline & Neutralization (\%) & $\mathrm{HI}$ assay & \\
\hline A/Vietnam//203/04 & 100 & + & 12,800 \\
\hline A/DK/Vietnam/376/05 & 100 & + & ND \\
\hline A/BhGs/Qing Hai/65/05 & 94 & - & $<$ \\
\hline $\mathrm{A} / \mathrm{CK} /$ lvory Coast/I787/06 & 88 & - & $200^{1}$ \\
\hline $\mathrm{A} /$ Zhe Jiang//6/06 & 78 & - & ND \\
\hline A/DK/Guangzhou/20/05 & 99 & + & $6,400^{2}$ \\
\hline A/Indonesia/CDC597/06 & 99 & - & ND \\
\hline A/Indonesia/5/05 & 5 & - & $<3$ \\
\hline $\mathrm{A} / \mathrm{CK} /$ Indonesia/R60/05 & 0 & - & ND \\
\hline
\end{tabular}

${ }^{a}$ assays performed using humanized VN04-2 antibody at $2 \mathrm{ug} / \mathrm{mL}$ ${ }^{b}$ assay data taken from Chen et al [I I] performed using the mouse VN04-2 antibody (I5A3) of unknown concentration; data obtained with virus exhibiting identical mutations relative to $A / V i e t n a m / I 203 /$ 04, 'MDk/JX/2 I36/05, 2MDk/JX//653/, and ${ }^{3} \mathrm{Ck} /$ Wajo/BBVM/05

H5N1 viruses circulating in Indonesia, VN04-2 may provide protection against $\mathrm{H} 5 \mathrm{~N} 1$ viruses from all other regions.

\section{Competing interests}

The authors declare that they have no competing interests.

\section{Authors' contributions}

APCL, OEE and BJH conceived the study. APCL and BJH planned the experimental design, performed the baculovirus and VLP work and drafted the manuscript. SKKW participated in the design and performed of HA1 cloning strategies. AHYC and CEZC helped with HA1 cloning and provided general technical assitance. All authors critically reviewed and approved the final manuscript.

\section{Acknowledgements}

We would like to thank Richard Webby for providing the CDNA to the VN04-2 mAB; our colleagues; Dr Gary Lau for providing the cDNA encoding HA2 of A/Vietnam/ I 203/04, Kevin Lim and Carol Leong for perform the Biacore analysis and Dr Tan Yik Joo, Institute of Molecular and Cell Biology, Singapore for the kind gift of the vector $\mathrm{pXJ}$.

This research was supported by Defence Science and Technology Agency Singapore, Future Systems Directorate, Ministry of Defence Singapore.

\section{References}

I. Claas EC, Osterhaus AD, van Beek R, De Jong JC, Rimmelzwaan GF, Senne DA, Krauss S, Shortridge KF, Webster RG: Human influenza A H5NI virus related to a highly pathogenic avian influenza virus. Lancet $1998,351: 472-477$.

2. de Jong JC, Claas EC, Osterhaus AD, Webster RG, Lim WL: A pandemic warning? Nature 1997, 389:554.

3. Yuen KY, Chan PK, Peiris M, Tsang DN, Que TL, Shortridge KF, Cheung PT, To WK, Ho ET, Sung R, Cheng AF: Clinical features and rapid viral diagnosis of human disease associated with avian influenza A H5NI virus. Lancet |998, 35 I:467-47|.

4. Fouchier R, Kuiken T, Rimmelzwaan G, Osterhaus A: Global task force for influenza. Nature 2005, 435:419-420.

5. Webster RG, Govorkova EA: H5N I influenza-continuing evolution and spread. N Engl J Med 2006, 355:2174-2177.
6. World: Cumulative Number of Confirmed Human Cases of Avian Influenza A/(H5NI) Reported to WHO on II January 2008 Healh Organization Epidemic and Pandemic Alert and Response 2008 [http://www.who.int/csr/disease/avian influenza/country/ cases table 2008 0l 1 l/en/index.html]

7. Simmons CP, Bernasconi NL, Suguitan AL, Mills K, Ward JM, Chau NV, Hien TT, Sallusto F, Ha do Q, Farrar J, et al.: Prophylactic and therapeutic efficacy of human monoclonal antibodies against H5NI influenza. PLoS Med 2007, 4:el78.

8. Hanson BJ, Boon AC, Lim AP, Webb A, Ooi EE, Webby RJ: Passive immunoprophylaxis and therapy with humanized monoclonal antibody specific for influenza A H5 hemagglutinin in mice. Respir Res 2006, 7:126.

9. Lu J, Guo Z, Pan X, Wang G, Zhang D, Li Y, Tan B, Ouyang L, Yu X: Passive immunotherapy for influenza $A$ H5NI virus infection with equine hyperimmune globulin $\mathbf{F}\left(\mathbf{a b}^{\prime}\right) \mathbf{2}$ in mice. Respiratory Research 2006, 7:43.

10. Zhou B, Zhong N, Guan Y: Treatment with convalescent plasma for influenza $\mathbf{A}(\mathbf{H 5 N I})$ infection. N Engl J Med 2007, 357:|450-|45|.

II. Chen H, Smith GJ, Li KS, Wang J, Fan XH, Rayner JM, Vijaykrishna D, Zhang JX, Zhang LJ, Guo CT, et al:: Establishment of multiple sublineages of $\mathrm{H} 5 \mathrm{NI}$ influenza virus in Asia: Implications for pandemic control. Proc Natl Acad Sci USA 2006, 103:2845-2850.

12. Hoffmann E, Lipatov AS, Webby RJ, Govorkova EA, Webster RG: Role of specific hemagglutinin amino acids in the immunogenicity and protection of $\mathrm{H} 5 \mathrm{NI}$ influenza virus vaccines. Proc Natl Acad Sci USA 2005, I02: 129 | 5- 12920.

13. Bao Y, Bolotov P, Dernovoy D, Kiryutin B, Zaslavsky L, Tatusova T, Ostell J, Lipman D: The Influenza Virus Resource at the National Center for Biotechnology Information. J Virol 2008, 82:596-60I.

14. Stevens J, Blixt O, Tumpey TM, Taubenberger JK, Paulson JC, Wilson IA: Structure and receptor specificity of the hemagglutinin from an H5NI influenza virus. Science 2006, 3 I 2:404-4 I0.

15. Brown LE, Murray JM, White DO, Jackson DC: An analysis of the properties of monoclonal antibodies directed to epitopes on influenza virus hemagglutinin. Arch Virol 1990, I | 4: I-26.

16. Szecsi J, Boson B, Johnsson P, Dupeyrot-Lacas P, Matrosovich M, Klenk HD, Klatzmann D, Volchkov V, Cosset FL: Induction of neutralising antibodies by virus-like particles harbouring surface proteins from highly pathogenic $\mathrm{H} 5 \mathrm{NI}$ and $\mathrm{H7NI}$ influenza viruses. Virol J 2006, 3:70.

17. Kolokoltsov AA, Wang E, Colpitts TM, Weaver SC, Davey RA: Pseudotyped viruses permit rapid detection of neutralizing antibodies in human and equine serum against Venezuelan equine encephalitis virus. Am J Trop Med Hyg 2006, 75:702-709.

18. Kolokoltsov AA, Weaver SC, Davey RA: Efficient functional pseudotyping of oncoretroviral and lentiviral vectors by Venezuelan equine encephalitis virus envelope proteins. J Virol 2005, 79:756-763.

19. World: Towards a unified nomenclature system for the highly pathogenic $\mathbf{H 5 N}$ I avian influenza viruses Healh Organization Epidemic and Pandemic Alert and Response 2007 [http:// www.who.int/csr/disease/avian influenza/guidelines/nomenclature/ en/index.html]

Publish with Biomed Central and every scientist can read your work free of charge

"BioMed Central will be the most significant development for disseminating the results of biomedical research in our lifetime. "

Sir Paul Nurse, Cancer Research UK

Your research papers will be:

- available free of charge to the entire biomedical community

- peer reviewed and published immediately upon acceptance

- cited in PubMed and archived on PubMed Central

- yours - you keep the copyright 